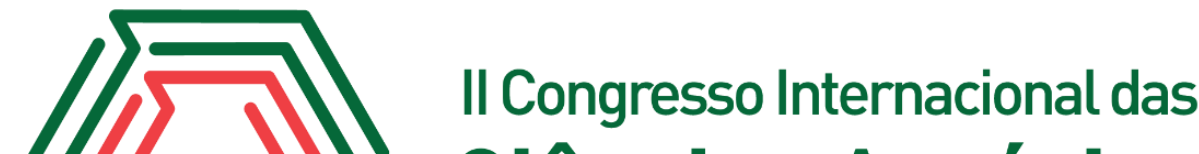 Ciências Agrárias COINTER - PDVAgro 2017
}

\section{MEDIÇÃO DE VAZÃO EM UM CANAL FLUVIAL UTILIZANDO O MÉTODO DO FLUTUADOR}

\author{
Apresentação: Pôster
}

Jade Cristynne Franco Bezerra ${ }^{1}$; Joaquim Gabriel Siqueira Dias ${ }^{2}$; Ágta Thiala de Souza Oliveira ${ }^{3}$; Alaene Teixeira Ribeiro ${ }^{4}$; Rossini Daniel ${ }^{5}$

\section{Introdução}

A bacia hidrográfica é considerada a mais adequada unidade de planejamento para uso e exploração dos recursos naturais. (RODRIGUES et al., 2008). Na gestão e gerenciamento dos recursos hídricos, os dados da vazão em canais fluviais permitem a elaboração de projetos de irrigação, análise de processo de outorga e dimensionamento de barragens entre outras aplicações (RIOS, 2011). Desta maneira, a avaliação das características hidrológicas é fundamental para proporcionar o manejo e gerenciamento adequado de uma bacia hidrográfica (MAURO et al., 2004).

Tendo em vista a grande importância dos dados de vazão e a dificuldade para sua obtenção, faz se necessário o estudo de técnicas alternativas para medição de vazão com uso de equipamentos com custos acessíveis, já existem vários métodos e equipamentos para obtenção desta, com diferentes aplicações e limitações, que dependem das características físicas do rio, da disposição de equipamentos, da experiência do operador, da precisão desejada, entre outros (LUZ et al., 2016)

Alguns são indicados para trabalhos em cursos d'água de pequeno e médio porte, e outros para médio e grande porte. A escolha entre as formas de medição de vazão está muitas vezes ligada à disponibilidade dos equipamentos, custos e ao tempo de coleta de dados que estes necessitam, portanto, diante desse contexto, objetivou-se determinar a vazão em um curso d'água utilizando o método do flutuador em uma fazenda no município de Paragominas - PA.

\section{Fundamentação Teórica}

\footnotetext{
${ }^{1}$ Discente de Engenharia Florestal, Universidade Federal Rural da Amazônia, jadefranco9@gmail.com ${ }^{2}$ Discente de Engenharia Florestal, Universidade Federal Rural da Amazônia, joaquimgdias@gmail.com ${ }^{3}$ Discente de Engenharia Florestal, Universidade Federal Rural da Amazônia, agtathiala@hotmail.com ${ }^{4}$ Discente de Engenharia Florestal, Universidade Federal Rural da Amazônia, alaene.ribeiro@hotmail.com ${ }^{5}$ Doutor em Ciências Agrárias, Universidade Federal Rural da Amazônia, rossini.daniel@ufra.edu.br
} 
Fioravanti (2009) relata os efeitos do desmatamento sobre os recursos hídricos e bacias hidrográficas, o autor descreve que a remoção da cobertura vegetal causa alterações, num primeiro momento aumentando e depois reduzindo o volume de água dos principais rios de uma região.

O método do flutuador consiste em determinar a velocidade de deslocamento de um objeto flutuante, medindo o tempo utilizado para o seu deslocamento num determinado trecho de rio de comprimento conhecido (SANTOS et al., 2001). Trabalhos com a utilização do método de flutuador ainda são recentes, autores como Bonifácio \& Freire (2013) e Silva (2016); utilizaram este método para a medição de vazão de rios e obtiveram bons resultados.

Este estudo servirá de base para pesquisas futuras, pois estudar o comportamento hidrológico desse córrego em períodos de cheia e estiagem onde a vazão diminui consideravelmente. Isso trará informações importantes sobre comportamento desse afluente do rio Uraim, que é um rios importantes para região e fonte de abastecimento do município.

\section{Metodologia}

O estudo foi realizado em um córrego localizado dentro da Fazenda Rancho Fundo no município de Paragominas, na mesorregião sudeste do Pará. Nesse trecho avaliado, é acompanhado por uma mata ciliar de ambos os lados. O município possui clima do tipo quente e úmido, com temperatura média anual de $26,3^{\circ} \mathrm{C}$ e a pluviosidade média de 1.800 milímetros anuais, com um período chuvoso concentrado entre os meses de dezembro a maio, e outro mais seco entre junho e novembro (PINTO et al., 2009).

Para a realização do teste foi necessário a escolha de um melhor ponto nos dois trechos do córrego e nesses pontos foram realizados os seguintes procedimentos: medição da largura do canal em oito seções, com auxílio de uma trena. Posteriormente, essa largura foi subdividida em quatro pontos equidistantes para medição da profundidade em cada seção (Figura 1a), para isso foi utilizada uma baliza de 2 metros.

A determinação da velocidade média da água em cada trecho foi obtida pelo método do flutuador. Foram utilizados uma boia de isopor que serviu como objeto flutuante e um cronômetro para determinação do tempo em que o flutuador levava para percorrer $15 \mathrm{~m}$ em cada trecho analisado. (Figura 1b). Em cada trecho, o procedimento foi repetido três vezes para melhor obtenção dos resultados. Após a obtenção das variáveis, realizou-se a tabulação dos dados utilizando o software Microsoft Excel 2016. 
A)

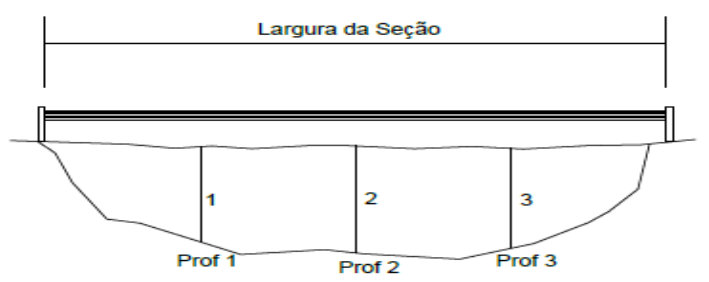

B)

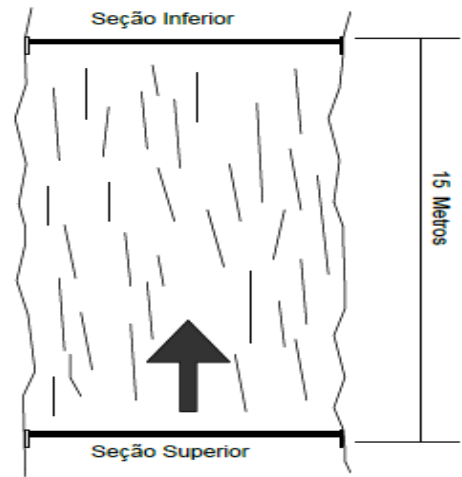

A velocidade (v) foi determinada pela divisão da distância percorrida pelo flutuador e a média das repetições dos tempos entre a seção superior e inferior.

$$
v=\frac{\Delta s}{\Delta t}
$$

Onde:

$\mathrm{v}=$ velocidade média $\left(\mathrm{m} \mathrm{s}^{-1}\right)$

$\Delta s=$ distância entre as seções $(\mathrm{m})$

$\Delta t=$ variação de tempo $(\mathrm{s})$

Para o cálculo da área utilizou-se o método de batimetria, que consiste na utilização de papel milimetrado para determinação da variável. Assim foram calculadas a área da seção superior e a área da seção inferior, trecho por onde passou o flutuador, então foi realizado a média de ambas áreas da seção. A vazão total pelo método do flutuador é dada pelo do produto da velocidade média corrigida pela área de seção transversal média (BONIFÁCIO \& FREIRE, 2013). Palhares et al. (2007) indicam coeficiente de correção entre 0,80 e 0,90 devido haver diferença na velocidade de escoamento em pontos superficiais e mais profundos de um curso d'água.

$$
Q=\bar{v} * \bar{A}
$$

Onde:

\begin{tabular}{l|l|l}
$\mathrm{Q}=$ Vazão em $\mathrm{m}^{3} \mathrm{~s}^{-1}$ & $\bar{V}=$ Velocidade $\times 0,85\left(\mathrm{~m} \mathrm{~s}^{-1}\right)$ & $\bar{A}=$ Média das duas áreas de seção $\left(\mathrm{m}^{2}\right)$
\end{tabular}

\section{Resultados e Discussões}

Os resultados da caracterização morfológica (largura, profundidade média e área das seções) ao longo curso d’água, são apresentados na Tabela 1. Observou-se que as seções do canal, apresentam profundidades e largura de leito próximo, no entanto, apresenta a área das seções distintas e proporciona características hidráulicas diferentes. 
Tabela 1. Características morfológicas do canal

Características Morfológicas

\begin{tabular}{lllllllll}
\hline & Seção 1 & Seção 2 & Seção 3 & Seção 4 & Seção 5 & Seção 6 & Seção 7 & Seção 8 \\
\hline Largura (m) & 5.60 & 7.80 & 5.40 & 7.90 & 6.30 & 7.04 & 5.40 & 6.80 \\
\hline $\begin{array}{l}\text { Profundidade } \\
\text { média (m) }\end{array}$ & 0.85 & 0.85 & 0.94 & 0.81 & 0.91 & 0.98 & 1.07 & 0.92 \\
\hline Área $\left(\mathbf{m}^{2}\right)$ & 3.95 & 4.75 & 4.07 & 5.30 & 5.02 & 6.07 & 4.81 & 5.66 \\
\hline
\end{tabular}

Conforme Braga et al., (2015), com o método do flutuador, a velocidade da água é, geralmente, diferenciada de um ponto para outro dentro da seção, ademais, em uma coluna de água a velocidade da mesma pode ser diferenciada conforme a profundidade. Desse modo, de acordo com a tabela 2, observa-se que a velocidade média superficial apresentam resultados semelhantes nas diferentes seções do canal, o que pode ser influenciado pelos resultados da proximidade entre a profundidade média exposta na tabela 1.

Sabe-se que, pela equação da continuidade, a vazão é diretamente proporcional a velocidade e que, além da largura de um curso d’água, a presença de remansos e redemoinhos pode interferir na medição desta variável (SANTOS et al.,2001). Assim, pode-se observar que as seções que apresentaram menores valores de velocidade média, consequentemente, apresentaram menores valores de vazão (Tabela 2). Isto pode ser justificado, pela observação de fenômenos de redemoinhos e remansos, ocasionados pela presença de obstáculos (troncos de madeira, serapilheira) ao longo do canal, os quais podem ter reduzido a velocidade do flutuador e, por conseguinte a vazão medida pelo flutuador.

Tabela 2. Valores médios referentes à área, velocidade e vazão do córrego.

\begin{tabular}{cccc}
\hline Seções & Área $\left(\mathbf{m}^{\mathbf{2}}\right)$ & Velocidade $(\mathbf{m} / \mathbf{s})$ & Vazão $\left(\mathbf{m}^{\mathbf{3}} / \mathbf{s}\right)$ \\
\hline Seção 1-2 & 4.35 & 0.22 & 0.95 \\
\hline Seção 3-4 & 4.69 & 0.26 & 1.23 \\
\hline Seção 5-6 & 5.55 & 0.20 & 1.12 \\
\hline Seção 7-8 & 5.24 & 0.22 & 1.16 \\
\hline
\end{tabular}

Vale ressaltar que, a variação dos resultados referentes à vazão é momentânea, e pode variar durante o período chuvoso da região, que é normalmente marcado nos meses de fevereiro a junho.

\section{Conclusões}

A determinação de vazão com a utilização do flutuador não necessita de investimento financeiro elevado, os resultados serão de menor confiabilidade técnica em comparação a outros 
métodos utilizados, contudo é possível ter uma boa noção da vazão em curso d'água. Desse modo é recomendado o uso do método do flutuador em corpos d'água de pequeno porte e quando não houver outro método mais preciso.

\section{Referências}

BONIFÁCIO, C. M.; FREIRE, R. Comparação de três métodos para a medição da vazão e velocidade aplicados em dois cursos d'água da bacia do Ribeirão Maringá. Periódico Eletrônico Fórum ambiental da Alta Paulista, v. 9, n. 2, p. 406-415, 2013.

BRAGA, C. C.; CABRAL, J. B. P.; GENTIL, W. B.; OLIVEIRA, S. F.; BATISTA, D. F.; ROCHA, I. S.; BARCELOS, A. A. Avaliação de determinações de vazão com o método do flutuador e com ACDP. In: SIMPÓSIO BRASILEIRO DE RECURSOS HÍDRICOS, 21.Anais..., 2015, Brasília: Associação Brasileira de Recursos Hídricos, 2015. p. 01-06.

FIORAVANTI, C. Terra seca, rios cheios. Pesquisa Fapesp, Ed. 164, Outubro, 2009.

LUZ, Ana Mara Murta et al. Congresso Técnico Científico da Engenharia e da Agronomia. In: CONGRESSO TÉCNICO CIENTÍFICO DA ENGENHARIA E DA AGRONOMIA, 73., 2016, Monte Carlos. Anais... . Foz do Iguaçu: SOEA, 2016. v. 5, p. 1 - 5.

RIOS, F. P.; FORMIGA, K. T. M.; ALVES, P. L.; OLIVEIRA, V. T. Estudo Comparativo entre Métodos de Medição de Vazão em Cursos D’água. In: XIX Simpósio Brasileiro de Recursos Hídricos, 2011, Maceió: ABRH, Anais..., 17p, 2011.

RODRIGUES, F. M.; PISSARRA, T. C. T.;CAMPOS, S. Caracterização morfométrica da microbacia hidrográfica do córrego da Fazenda da Glória, município de Taguaritinga, SP. Irriga,v.13, n.3, p.310-322, 2008.

MAURO, FERNANDO; VANZELA, LUIZ SERGIO; TANGERINO, FERNANDO BRAZ. Determinação dos Erros Envolvidos nas Medições de Vazão pelo Método do Flutuador Integrador e do Vertedor Triangular. Congresso Brasileiro de Engenharia Agrícola, São Pedro, 2004.

SANTOS, I.; FILL, H. D.; SUGAI, M. R. V. B.; BUBA, H.; KISHI, R. T.; MARONE, E.; LAUTERT, L. F. Revista Hidrometria aplicada. Curitiba: Instituto de Tecnologia para o Desenvolvimento, LACTEC, 2001.

SILVA, V. R.; A utilização do método de flutuadores na medição da vazão do rio Biguaçu no Estado de Santa Catarina. In: ENCONTRO NACIONAL DE GEÓGRAFOS, São Luís. Anais. São Luís:2016.

PALHARES, J. C. P. et al. Medição da Vazão em Rios pelo Método do Flutuador. Comunicado técnico. Concórdia: Embrapa, 7 p. 2007.

PINTO, A.; et al.. Diagnóstico Socioeconômico e Florestal do Município de Paragominas. Relatório Técnico. Belém/PA: Instituto do Homem e Meio Ambiente da Amazônia - Imazon. 65 p. 2009. 